\title{
Safety evaluation of highly purified fullerenes (HPFs): based on screening of eye and skin damage
}

\author{
Hisae Aoshima1, Yasukazu Saitoh², Shinobu Ito1, Shuichi Yamana1 and Nobuhiko Miwa² \\ ${ }^{1}$ Vitamin C60 BioResearch Corporation, Tatsunuma Tatemono Bldg, 9F, 1-3-19, Yaesu, Chuo-ku, \\ Tokyo 103-0028, Japan \\ ${ }^{2}$ Laboratory of Cell-Death Control Biotechnology, Faculty of Life and Environmental Sciences, Prefectural \\ University of Hiroshima, 562 Nanatsuka, Shobara, Hiroshima 727-0023, Japan
}

(Received May 18, 2009; Accepted June 10, 2009)

\begin{abstract}
The safety of highly purified fullerenes (HPFs) for utilization as antioxidants in the cosmetic industry was evaluated by studying the toxicity and effects on laboratory animals, human epidermal keratinocytes, and human fibroblasts. The HPFs did not induce primary or cumulative skin irritation, skin sensitization, skin photosensitization or contact phototoxicity. No skin reaction was observed in the patch test on human skin. In the primary eye-irritation test on rabbits, conjunctival redness and corneal epithelial defects were observed in all animals of the eye-unwashed group at $1 \mathrm{and} 24 \mathrm{hr}$ after application, but disappeared by $48 \mathrm{hr}$ after application. The irritation may have been caused by administration of insoluble fullerene powder. Therefore, the HPFs were assessed as "minimally irritating" in the eye-irritation test. By comparing these results with previously published data, we concluded that HPFs can be safely used in cosmetic ingredients for human skin application. This is the first study performing all the toxicity tests on the same fullerene material for approval as an additive in quasi-drugs.
\end{abstract}

Key words: Fullerene, Safety evaluation, Quasi-drug

\section{INTRODUCTION}

The potent antioxidant activity of fullerenes and their derivatives as a new class of carbon materials has attracted considerable attention in order to develop novel applications of fullerenes in the cosmetic and pharmaceutical industries. It has been demonstrated that water-soluble fullerenes protect human skin keratinocytes from reactive oxygen species generated by ultraviolet (UV) irradiation or peroxylipids (Xiao et al., 2005, 2006). Fullerenes also inhibit UVA-induced melanogenesis in human melanocytes and skin tissue (Xiao et al., 2007). Furthermore, a water-soluble fullerene, modified by oligoethyleneglycol bridges, has shown potential in secondary progressive multiple sclerosis (Basso et al., 2008). Several carboxyfullerenes have cytoprotective and neuroprotective activities (Beuerle et al., 2008); fullerenol $\left(\mathrm{C}_{60} \mathrm{OH}_{24}\right)$ prevented mitochondrial dysfunction in a cellular model of Parkinson's disease (Cai et al., 2008) and a water-soluble fullerene prevented degeneration of articular cartilage in osteoarthritis (Yudoh et al., 2007).

As fullerenes are one of the most typical nanomate- rials, there is a growing concern regarding their safety. Therefore, toxicity studies on fullerenes and their derivatives have been performed in recent years by using laboratory animals, aquatic organisms, and in vivo and in vitro microorganismal systems around the world. In one of the latest studies, by using oligonucleotide microarrays, Fujita et al. (2009) demonstrated that fullerene $\mathrm{C}_{60}$ in Tween-80 did not induce significant inflammation and tissue injury on inhalation exposure to rats. Fullerenes suspended in methylcellulose in Tween- 80 also showed no peritoneal adhesion, fibrous thickening, or tumor induction when applied intraperitoneally in mice (Takagi et al., 2008). These studies have shown the advantages of fullerenes as a nontoxic substance. Governments and intellectuals in several countries are currently attempting to formulate guidelines for industrial application of nanomaterials, including fullerenes. Therefore, it is important to continue examining and accumulating data on toxicity and/or safety from various angles. Thus far, all evaluations meeting the standards for application as an external-use quasi-drug have not been conducted on the same substance from a single fullerene source. Therefore, we aimed to

Correspondence: Hisae Aoshima (E-mail: hisae.aoshima@vc60.com) 
confirm the safety of highly purified fullerenes (HPFs) for utilization as excellent and stable antioxidants in cosmetic ingredients. Our previous study demonstrated no evidence of inhalation toxicity, mutagenic potential or chromosomal aberration. In this study, we investigated the toxicity potential of HPFs in primary and cumulative skin-irritation, skin-sensitization, skin-photosensitization, contactphototoxicity, clinical patch and eye-irritation tests.

\section{MATERIALS AND METHODS}

\section{Test materials}

The test materials were as follows: highly purified fullerenes (HPFs; mixture of $\mathrm{C}_{60}$ and $\mathrm{C}_{70}$, fullerite; sublimed technical grade, $99.5 \%$ purity) from Vitamin C60 BioResearch Corp. (Tokyo, Japan); propylene glycol (PG), acetone, sodium lauryl sulfate (SLS), ethyl alcohol, 2,4-dinitrochlorobenzene (DNCB), and 3,4',5-tribromosalicylanilide (TBS) from Wako Pure Chemical Industries, Ltd. (Osaka, Japan); Freund's complete adjuvant (FCA) from Becton, Dickinson and Company (Franklin Lakes, NJ, USA); injection solvent from Otsuka Pharmaceutical Co., Ltd. (Tokyo, Japan); white petrolatum from Oriental Pharmaceutical Co., Ltd. (Yamagata, Japan); and 8-methoxypsolaren (8-MOP) from Tokyo Chemical Industry Co., Ltd. (Tokyo, Japan). Fullerenes dispersed in PG were used for all tests, except the eye-irritation and patch tests. Polyvinylpyrrolidone (PVP) and cyclodextrin (CyD) were purchased from ISP Japan, Ltd. (Tokyo, Japan) and Cyclo Chem Co., Ltd. (Hyogo, Japan), respectively.

\section{Animals and dose schedule}

Male Japanese white rabbits (Kbl:JW) aged 11 weeks from Kitayama Labes Co., Ltd. (Nagano, Japan) were used for the tests on primary eye irritation and primary and cumulative skin irritation. Male Hartley guinea pigs aged 6 weeks from Japan SLC, Inc., (Shizuoka, Japan) were used for the skin-sensitization, skin-photosensitization, and contact-phototoxicity tests. The animals were housed individually in stainless steel cages under a controlled atmosphere with a temperature range of $19.0-25.0^{\circ} \mathrm{C}$ and mean relative humidity of $35.0-75.0 \%$ on a 12-hr light-dark cycle (lights on at 7:00 a.m.) Animal chow (rabbit: LRC4 (Oriental Yeast Co., Ltd., Tokyo, Japan); guinea pig: Labo G standard (Nosan Corp., Kanagawa, Japan)) and sterilized water were provided ad libitum. After quarantine and acclimatization to the environmental conditions for 5 days, the animals found to be in good health were randomly allocated to groups on a body weight basis. These studies were conducted in com- pliance with the Guiding Principles for the Care and Use of Laboratory Animals of the Japanese Pharmacological Society and the animal care guidelines used in our laboratories, as approved by the Tokyo Women's Medical University Ethics Committee on Animal Care and Use.

\section{Irritation studies}

All irritation studies were performed under a good laboratory practice (GLP) standard in Mitsubishi Chemical Safety Institute, Ltd. (Standards for Conduct of Non-clinical Studies on the Safety of Drugs, MHW, Ordinance No. 21, March 26, 1997). Primary and cumulative skinirritation tests were conducted on rabbits according to the Draize et al. (1944) method. In the primary skin-irritation test, the backs of three male rabbits were shaved free of hair (four sites each of $\sim 2.5 \times 2.5 \mathrm{~cm}^{2}, \sim 6 \mathrm{~cm}^{2}$ ), and test samples $(0.3-\mathrm{ml}$ PG or 0.5 -g HPFs in $0.3-\mathrm{ml} P G)$ were introduced under gauze. The patches were secured for a 24-hr exposure period with impervious materials, following which the patches and residual test materials were removed with water and any skin reactions were evaluated at 0-48 hr after removal.

In the cumulative skin-irritation test, two application sites were prepared dorsally on 5 animals $\left(\sim 5 \times 5 \mathrm{~cm}^{2}\right.$ each). For each animal, 20-mg HPFs in 0.2-ml PG was applied to the right site and 0.2-ml PG was applied to the left site. After the second application, the same treatment was repeated after any suspension adhering to the skin was rinsed off with approximately 5-ml PG and 10$\mathrm{ml}$ water. A collar (Elizabethan collar) was fitted around each animal's neck to protect the application sites immediately after application until the end of the observation period. Clinical signs were observed daily from the day of application to the end of the observation period. The body weight of all animals was measured with an electronic balance (EB-16KS; Shimadzu Corp., Kyoto, Japan) on the first application day and after $72 \mathrm{hr}$ in the primary test and on days 8 and 15 in the cumulative test.

The primary eye-irritation test was conducted on six rabbits according to the Kay and Calandra (1962) method, by instilling HPFs $(0.1 \mathrm{~g})$ into the lower conjunctival sac of each rabbit's right eye. The eyelids were then gently held together for $1 \mathrm{sec}$ to prevent loss of the test substance. In the eye-unwashed group $(n=3)$, the treated eye remained unwashed following the application. In the eye-washed group $(n=3)$, the treated eye was rinsed for $30 \mathrm{sec}$ beginning $30 \mathrm{sec}$ after treatment with $45 \mathrm{ml}$ of isotonic sodium chloride solution. The contralateral eye remained untreated and served as a control. A collar (Elizabethan collar) was fitted around each rabbit's neck to protect the eyes from shortly before application until the 
Safety evaluation of fullerenes

final observation. Ocular irritation reactions were examined using fluorescein. Sodium fluorescein was instilled in the treated eye and rinsed out with isotonic sodium chloride solution. The cornea was then fully examined for any lesion under UV light (UVL-56; Funakoshi Co., Ltd., Tokyo, Japan) $24 \mathrm{hr}$ after instillation. Opacity of the cornea; the area of opacity; defects of the iris; and redness, chemosis, and discharge of the conjunctivae were scored at $1,24,48$, and $72 \mathrm{hr}$, and 4 days posttreatment.

The skin-sensitization test was conducted on 30 guinea pigs in accordance with the Guidelines for Toxicity Studies of Drugs (Notification No. 24 of the First Evaluation and Registration Division, Pharmaceutical Affairs Bureau (PAB), September 11, 1989). In the induction phase, on the day after skin clipping (day 1), $0.1 \mathrm{ml}$ of water and FCA emulsion (25 and 50\% [w/v]) was injected intradermally into four sites. Next, adhesive plaster for a patch test was coated with $0.1 \mathrm{ml}$ of each dosing formulation and applied to the four abraded sites. The induction procedure involved four $0.1-\mathrm{ml}$ intradermal injections of test materials containing $50 \mathrm{mg}$ of HPFs (suspended in 50 or $25 \%$ [w/v] PG; $n=10), 0.1-\mathrm{ml} \mathrm{PG}(n=10), 0.05 \%(\mathrm{w} /$ v) DNCB in acetone (as a positive control; $n=5$ ), or 0.1 $\mathrm{ml}$ acetone $(n=5)$. Abrasion and application of the dosing formulations were repeated daily for three consecutive days. On day 8 , the skin over the induction area was clipped again and $0.2 \mathrm{ml}$ of $10 \%$ SLS in white petrolatum was applied. On day 9, a cotton flannel patch was coated with $0.2 \mathrm{ml}$ of each dosing formulation and applied to the injection area. On day 22, $0.01 \mathrm{ml}$ of the dosing formulations was directly spread in a circular pattern onto the clipped skin. The skin reactions at the application sites were observed macroscopically 24 and $48 \mathrm{hr}$ after day 22 , and were scored separately for erythema and edema according to the Sato et al. (1981) criteria. The skinsensitization potential was classified according to the Magnusson and Kligman (1969) criteria.

The skin-photosensitization test was also conducted on 20 male guinea pigs according to the Guidelines for Toxicity Studies of Drugs. Test materials $(0.1 \mathrm{ml})$ containing either 50-mg HPFs or TBS as a positive control were applied to the stripped application areas, which were then irradiated with a $10 \mathrm{~J} / \mathrm{cm}^{2}\left(5.23\right.$ or $-5.41 \mathrm{~mW} / \mathrm{cm}^{2}, 30-31$ min) long-wavelength UV lamp (FL40S-BLB, Toshiba Lighting Technology Corp., Tokyo, Japan). The light intensity was measured with a luminometer (UVR-1 [sensor unit: UVR-36]; Topcon Corp., Tokyo, Japan). The procedures (i.e., stripping, application, and UV irradiation) were repeated daily for five consecutive days (days 1-5). The challenge was performed 22 days after the initiation of induction (i.e., on day 23). A $0.02-\mathrm{ml}$ dosing formula- tion was applied to one application site on each side, after which the right side of the application area was shielded from light by covering with an adhesive tape backed with aluminum foil. The application site was then irradiated with $10 \mathrm{~J} / \mathrm{cm}^{2}$ (3.14 or $3.30 \mathrm{~mW} / \mathrm{cm}^{2}, 50$ or $53 \mathrm{~min}$ ) longwavelength UV light applied through a 5-mm-thick glass filter to eliminate erythrogenic short-wavelength UV rays shorter than $320 \mathrm{~nm}$. The skin reactions at the application sites were observed macroscopically 24 and $48 \mathrm{hr}$ after the challenge, and were scored according to the Sato et al. (1981) criteria.

The contact-phototoxicity test was performed on 10 male guinea pigs according to the Morikawa et al. (1974) method. Test materials $(0.03 \mathrm{ml})$ containing $7.5-\mathrm{mg}$ HPFs $(n=10), 0.03-\mathrm{ml} \mathrm{PG}$, or $0.05 \%(\mathrm{w} / \mathrm{v}) 8$-MOP solution were symmetrically applied to the application sites on each side one day after the skin on the back of the trunk was clipped free of hair. After the application, the right side of the application area was protected from light by covering with an adhesive tape backed with aluminum foil and long-wavelength UV irradiation $\left(11.2 \mathrm{~J} / \mathrm{cm}^{2}\right.$, $3.77 \mathrm{~mW} / \mathrm{cm}^{2}, 50 \mathrm{~min}$ ) was initiated after $30 \mathrm{~min}$ of the application. Skin reactions at the application sites were observed macroscopically at 24, 48, and $72 \mathrm{hr}$ after UV irradiation and were scored according to the Magnusson and Kligman (1969) criteria.

\section{Clinical patch test}

The patch test was performed on the skin of 21 men and 24 women, aged 22-56 yr. The test sample (0.01-g HPFs) was placed on a Finn Chamber (Epitest Ltd., Oy, Tuusula, Finland) and applied to the ventral side of each subject's upper arm for $24 \mathrm{hr}$ in an occlusive condition. Skin reactions were evaluated 1 and $24 \mathrm{hr}$ after removing the test samples. The reaction was evaluated according to the International Contact Dermatitis Research Group (ISDRG) standard.

\section{RESULTS AND DISCUSSION}

\section{Preparation of HPFs}

Fullerenes were mainly synthesized by the combustion method or the arcing method. During fullerene synthesis by these methods, other polycyclic aromatic hydrocarbons such as anthracene, phenanthrene and corannulenes were also produced. Next, fullerenes were extracted using soluble solvents such as 1,3,5-trimethylbenzene, hexane, and toluene. It was difficult to completely eliminate the organic solvents and the above mentioned products produced during synthesis. Therefore, HPFs were purified by an established method whereby the remaining impurities 
and solvents were removed.

\section{Primary eye-irritation test}

Individual scores of the ocular reactions are shown in Fig. 1. Conjunctival redness (score 1) and discharge (score 2) were observed in all animals of the eye-unwashed group $(n=3)$ at $1 \mathrm{hr}$ after application, but disappeared by $48 \mathrm{hr}$ after application. Corneal epithelial defects were observed in all animals at $24 \mathrm{hr}$ after application, but also disappeared by $48 \mathrm{hr}$ after application. In the eye-washed group $(n=3)$, no ocular reactions were observed in any animal. The reactions in the eye-washed group disap- peared at an earlier stage than in the eye-unwashed group, indicating the effectiveness of eye washing in this study. The maximum weighted mean score in the eye-unwashed group with the Draize et al. (1944) method was 6.0, which was classified as "minimally irritating" with the Kay and Calandra (1962) method (Fig. 2). The slight reactions in the eye-unwashed group may have resulted from the physical effects frequently seen after ocular instillation of an insoluble fullerene powder (average particle size $=100-300 \mu \mathrm{m})$, such as our test substance. We considered that the instillation of HPFs did not induce a positive response, although the eye-unwashed group exhibited

(A) Eye- washed group

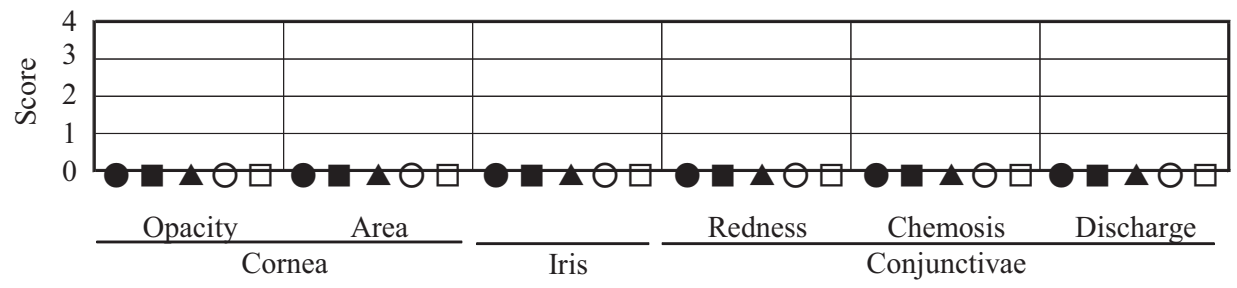

(B) Eye-unwashed group

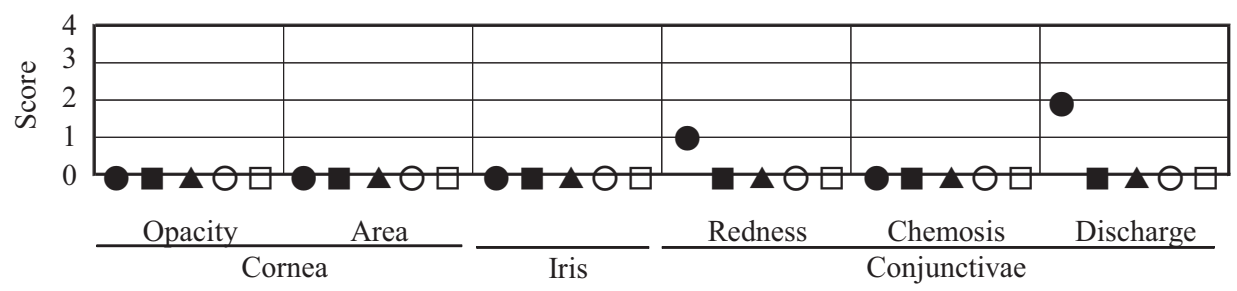

Fig. 1. Individual scores of ocular reactions.

$\bullet, 1 \mathrm{hr} ; \mathbf{\square}, 24 \mathrm{hr} ; \boldsymbol{\Delta}, 48 \mathrm{hr} ; \circ, 72 \mathrm{hr} ; \square, 4$ days.
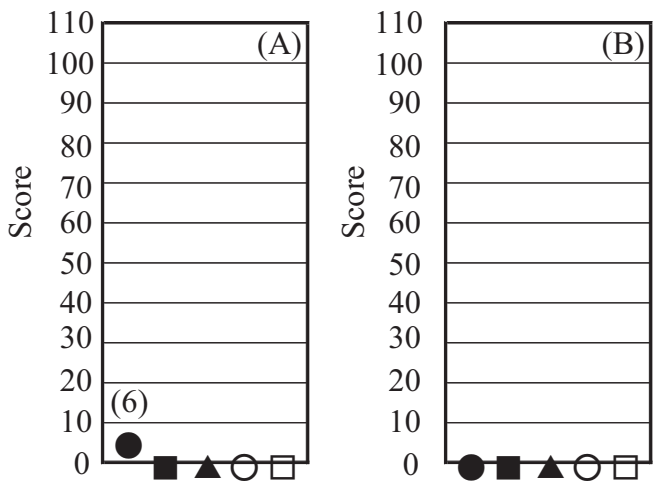

Fig. 2. Weighted total scores of ocular reactions according to Draize et al. (1944) method. (A), Eye-washed group; (B) Eyeunwashed group.

$\bullet, 1 \mathrm{hr} ; \mathbf{\mathbf { m }}, 24 \mathrm{hr} ; \boldsymbol{\Delta}, 48 \mathrm{hr} ;$, $72 \mathrm{hr} ; \square, 4$ days. 
Safety evaluation of fullerenes

Table 1. Skin reaction to the skin sensitization, skin photosensitization, and contact-phototoxicity tests

A. Skin sensitization test

\begin{tabular}{|c|c|c|c|c|c|c|}
\hline Group & $\begin{array}{l}\text { Induction } \\
\text { substance }\end{array}$ & $\begin{array}{l}\text { Number of } \\
\text { animals }\end{array}$ & $\begin{array}{l}\text { Challenge } \\
\text { substance }\end{array}$ & Time $(\mathrm{hr})^{a}$ & Mean response & $\begin{array}{c}\text { Sensitization rate } \\
(\%)^{e}\end{array}$ \\
\hline \multirow[t]{2}{*}{ Test substance } & $\begin{array}{l}\mathrm{HPFs} \\
(50 \mathrm{w} / \mathrm{v} \%)\end{array}$ & 10 & $\begin{array}{l}\text { HPFs } \\
(25 \mathrm{w} / \mathrm{v} \%)\end{array}$ & $\begin{array}{l}24 \\
48\end{array}$ & 0 & 0 \\
\hline & & & $\begin{array}{l}\text { Vehicle } \\
\text { (PG) }\end{array}$ & $\begin{array}{l}24 \\
48\end{array}$ & 0 & 0 \\
\hline \multirow[t]{2}{*}{$\begin{array}{l}\text { Control for test } \\
\text { substance }\end{array}$} & $\begin{array}{l}\text { Vehicle } \\
\text { (PG) }\end{array}$ & 10 & $\begin{array}{l}\text { HPFs } \\
(25 \mathrm{w} / \mathrm{v} \%)\end{array}$ & $\begin{array}{l}24 \\
48\end{array}$ & $\begin{array}{l}0 \\
0\end{array}$ & $\begin{array}{l}0 \\
0\end{array}$ \\
\hline & & & $\begin{array}{l}\text { Vehicle } \\
\text { (PG) }\end{array}$ & $\begin{array}{l}24 \\
48\end{array}$ & $\begin{array}{l}0 \\
0\end{array}$ & $\begin{array}{l}0 \\
0\end{array}$ \\
\hline \multirow[t]{2}{*}{ DNCB } & $\begin{array}{l}\text { DNCB } \\
(0.05 \mathrm{w} / \mathrm{v} \%)\end{array}$ & 5 & $\begin{array}{l}\text { DNCB } \\
(0.05 \mathrm{w} / \mathrm{v} \%)\end{array}$ & $\begin{array}{l}24 \\
48\end{array}$ & $\begin{array}{l}3.8 \\
3.8\end{array}$ & $\begin{array}{l}100 \\
100\end{array}$ \\
\hline & & & $\begin{array}{l}\text { Vehicle } \\
\text { (acetone) }\end{array}$ & $\begin{array}{l}24 \\
48\end{array}$ & $\begin{array}{l}0 \\
0\end{array}$ & $\begin{array}{l}0 \\
0\end{array}$ \\
\hline \multirow[t]{2}{*}{ Control for DNCB } & $\begin{array}{l}\text { Vehicle } \\
\text { (acetone) }\end{array}$ & 5 & $\begin{array}{l}\text { DNCB } \\
(0.05 \mathrm{w} / \mathrm{v} \%)\end{array}$ & $\begin{array}{l}24 \\
48\end{array}$ & $\begin{array}{l}0 \\
0\end{array}$ & $\begin{array}{l}0 \\
0\end{array}$ \\
\hline & & & $\begin{array}{l}\text { Vehicle } \\
\text { (acetone) }\end{array}$ & $\begin{array}{l}24 \\
48\end{array}$ & $\begin{array}{l}0 \\
0\end{array}$ & $\begin{array}{l}0 \\
0\end{array}$ \\
\hline
\end{tabular}

B. Skin photosensitization test

\begin{tabular}{|c|c|c|c|c|c|c|c|}
\hline Group & $\begin{array}{l}\text { Induction } \\
\text { substance }\end{array}$ & $\begin{array}{l}\text { Number } \\
\text { ofanimals }\end{array}$ & $\begin{array}{l}\text { Challenge } \\
\text { substance }\end{array}$ & $\mathrm{UV}^{b}$ & Time $(\mathrm{hr})^{c}$ & Mean response & $\begin{array}{c}\text { Sensitization } \\
\text { rate }(\%)^{e}\end{array}$ \\
\hline \multirow[t]{4}{*}{ Test substance } & $\begin{array}{l}\mathrm{HPFs} \\
(50 \mathrm{w} / \mathrm{v} \%)\end{array}$ & 10 & $\begin{array}{l}\text { HPFs } \\
(25 \mathrm{w} / \mathrm{v} \%)\end{array}$ & + & $\begin{array}{l}24 \\
48\end{array}$ & $\begin{array}{l}0 \\
0\end{array}$ & $\begin{array}{l}0 \\
0\end{array}$ \\
\hline & & & & - & $\begin{array}{l}24 \\
48\end{array}$ & $\begin{array}{l}0 \\
0\end{array}$ & $\begin{array}{l}0 \\
0\end{array}$ \\
\hline & & & $\begin{array}{l}\text { Vehicle } \\
\text { (PG) }\end{array}$ & + & $\begin{array}{l}24 \\
48\end{array}$ & $\begin{array}{l}0 \\
0\end{array}$ & $\begin{array}{l}0 \\
0\end{array}$ \\
\hline & & & & - & $\begin{array}{l}24 \\
48\end{array}$ & $\begin{array}{l}0 \\
0\end{array}$ & $\begin{array}{l}0 \\
0\end{array}$ \\
\hline \multirow[t]{4}{*}{ TBS } & $\begin{array}{l}\text { TBS } \\
(2 \mathrm{w} / \mathrm{v} \%)\end{array}$ & 5 & $\begin{array}{l}\text { TBS } \\
(2 \mathrm{w} / \mathrm{v} \%)\end{array}$ & + & $\begin{array}{l}24 \\
48\end{array}$ & $\begin{array}{l}4.6 \\
4.8\end{array}$ & $\begin{array}{l}100 \\
100\end{array}$ \\
\hline & & & & - & $\begin{array}{l}24 \\
48\end{array}$ & $\begin{array}{l}0 \\
0\end{array}$ & $\begin{array}{l}0 \\
0\end{array}$ \\
\hline & & & $\begin{array}{l}\text { Vehicle } \\
\text { (acetone) }\end{array}$ & - & $\begin{array}{l}24 \\
48\end{array}$ & $\begin{array}{l}0 \\
0\end{array}$ & $\begin{array}{l}0 \\
0\end{array}$ \\
\hline & & & & - & $\begin{array}{l}24 \\
48\end{array}$ & $\begin{array}{l}0 \\
0\end{array}$ & $\begin{array}{l}0 \\
0\end{array}$ \\
\hline \multirow[t]{4}{*}{ Negative Control } & $\begin{array}{l}\text { Non- } \\
\text { Treatment }{ }^{d}\end{array}$ & 5 & $\begin{array}{l}\text { Fullerenes } \\
(25 \mathrm{w} / \mathrm{v} \%)\end{array}$ & + & $\begin{array}{l}24 \\
48\end{array}$ & $\begin{array}{l}0 \\
0\end{array}$ & $\begin{array}{l}0 \\
0\end{array}$ \\
\hline & & & & - & $\begin{array}{l}24 \\
48\end{array}$ & $\begin{array}{l}0 \\
0\end{array}$ & $\begin{array}{l}0 \\
0\end{array}$ \\
\hline & & & $\begin{array}{l}\text { TBS } \\
(2 \mathrm{w} / \mathrm{v} \%)\end{array}$ & - & $\begin{array}{l}24 \\
48\end{array}$ & $\begin{array}{l}0 \\
0\end{array}$ & $\begin{array}{l}0 \\
0\end{array}$ \\
\hline & & & & - & $\begin{array}{l}24 \\
48\end{array}$ & $\begin{array}{l}0 \\
0\end{array}$ & $\begin{array}{l}0 \\
0\end{array}$ \\
\hline
\end{tabular}


H. Aoshima et al.

C. Contact-phototoxicity test

\begin{tabular}{|c|c|c|c|c|}
\hline Test materials & $\mathrm{UV}^{b}$ & Time $^{c}(\mathrm{hr})$ & Mean response & Positiverate (\%) ${ }^{e}$ \\
\hline \multirow[t]{2}{*}{$\begin{array}{l}\text { Fullerenes } \\
(25 \mathrm{w} / \mathrm{v} \%)\end{array}$} & + & $\begin{array}{l}24 \\
48 \\
72\end{array}$ & $\begin{array}{l}0 \\
0 \\
0\end{array}$ & $\begin{array}{l}0 \\
0 \\
0\end{array}$ \\
\hline & - & $\begin{array}{l}24 \\
48 \\
72\end{array}$ & $\begin{array}{l}0 \\
0 \\
0\end{array}$ & $\begin{array}{l}0 \\
0 \\
0\end{array}$ \\
\hline \multirow[t]{2}{*}{$\begin{array}{l}\text { Vehicle } \\
\text { (PG) }\end{array}$} & + & $\begin{array}{l}24 \\
48 \\
72\end{array}$ & $\begin{array}{l}0 \\
0 \\
0\end{array}$ & $\begin{array}{l}0 \\
0 \\
0\end{array}$ \\
\hline & - & $\begin{array}{l}24 \\
48 \\
72\end{array}$ & $\begin{array}{l}0 \\
0 \\
0\end{array}$ & $\begin{array}{l}0 \\
0 \\
0\end{array}$ \\
\hline \multirow[t]{2}{*}{$\begin{array}{l}8-\mathrm{MOP} \\
(0.005 \mathrm{w} / \mathrm{v} \%)\end{array}$} & + & $\begin{array}{l}24 \\
48 \\
72\end{array}$ & $\begin{array}{l}2.7 \\
3.0 \\
2.9\end{array}$ & $\begin{array}{l}100 \\
100 \\
100\end{array}$ \\
\hline & - & $\begin{array}{l}24 \\
48 \\
72\end{array}$ & $\begin{array}{l}0 \\
0 \\
0\end{array}$ & $\begin{array}{l}0 \\
0 \\
0\end{array}$ \\
\hline
\end{tabular}

${ }^{a}$ Time: time after challenge.

${ }^{b} \mathrm{UV}:+$, irradiated; -, non-irradiated.

${ }^{c}$ Time: time after UV irradiation.

${ }^{d}$ Animals received FCA injection and UV irradiation.

${ }^{e}$ Mean response and positive rate were calculated as follows at each observation point.

Skin reaction with a score of $\geq 1$ was classified as positive, and the sensitization or positive rate was calculated.

Mean score $=\frac{\text { Sum of score for skin reaction }}{\text { Number of animals }}$
Positive rate $(\%)=\frac{\text { Number of animals that showed positive skin reaction }}{\text { Number of animals }} \times 100$

temporary mild irritation.

\section{Primary and cumulative skin-irritation tests}

In the primary skin-irritation test, no evidence of erythema, edema, or any other skin reactions were observed on either intact or abraded skin of any animal with HPFs application sites. Coloring due to the test substance was observed in all animals at 24 and $48 \mathrm{hr}$ after application, but disappeared by $72 \mathrm{hr}$ after application. Similarly, no skin reactions were observed on either intact or abraded skin of any animals with PG application sites (data not shown). In the cumulative skin-irritation test, no dermal reactions were observed in any animals throughout the application period at both HPFs-treated and PG-treated sites. Coloring due to the test substance was observed in all animals from days 2 to 15 (data not shown). In the histopathological examination of extracted skin on the final observation day, epidermal thickening was observed at the HPFs-treated site in all the animals, and at the PG-treated site in some animals. The degree of change was slight and there were no differences between the findings at both application sites. Therefore, the histological finding was considered to have been induced by PG. In the untreated area, abnormal findings were not observed in any of the animals, suggesting that the HPFs did not induce 24-hr or cumulative skin irritation on consecutive daily applications to rabbit skin under our study conditions.

\section{Skin-sensitization test}

In the HPFs and control groups, no skin reactions were observed in any of the animals. Erythema (score 2 or 3) and edema (score 1 or 2) were observed at the DNCBtreated sites in all animals at 24 and $48 \mathrm{hr}$ after the challenge. The mean response at each observation point was 
Safety evaluation of fullerenes

calculated for each application site. The mean response at the DNCB-treated sites was 3.8 at both 24 and $48 \mathrm{hr}$ after the challenge (Table 1A). On the other hand, no skin reactions were observed at the acetone-treated sites in any animals. These results indicate that the HPFs had no skinsensitization potential in guinea pigs under our study conditions.

\section{Skin-photosensitization test}

No skin reactions were observed at the HPFs $(25 \mathrm{w} / \mathrm{v} \%$ dispersed in PG) application sites on either the UV-irradiated or non-irradiated sides. Erythema (score 2-4) and edema (score 1-3) were observed at the TBS application sites on the UV-irradiated side of all animals 24 and 48 hr after the challenge, with a mean response of 4.6 at 24 $\mathrm{hr}$ and 4.8 at $48 \mathrm{hr}$ after the challenge (Table 1B). On the other hand, no skin reactions were observed at the TBS application sites on the non-irradiated side and at the acetone-application sites on either the irradiated or non-irradiated side. No skin reactions were observed at the HPFs application sites on either the irradiated or non-irradiated side. Therefore, HPFs had no skin photosensitization potential in guinea pigs under these study conditions.

\section{Contact-phototoxicity test}

No skin reactions were observed at HPFs-treated sites on both UV-irradiated and nonirradiated sides in all animals (Table $1 \mathrm{C}$ ). In addition, no skin reactions were observed at PG-treated sites on either the irradiated or nonirradiated side in all animals. On the other hand, although skin reactions of score 1-3 were observed at 8-
MOP-treated sites on the irradiated side in all animals from $24 \mathrm{hr}$ after UV irradiation, no skin reactions were observed at these sites on the nonirradiated side. The highest mean score for the skin reaction at the 8-MOPtreated sites on the irradiated side was 3.0 at $48 \mathrm{hr}$ after UV irradiation (Table 1C). No abnormal clinical signs were observed in any animals from administration until final observation. These results suggest that the HPFs had no contact phototoxicity potential in guinea pigs under the study conditions.

\section{Patch test}

No skin reaction was observed at 1 and $24 \mathrm{hr}$ after removing the test materials in all human subjects (data not shown). Therefore, we concluded that the HPFs had minimal potential to elicit an irritation reaction.

In conclusion, this is the first study performing all the toxicity tests on the same fullerene material for approval as an additive in external-use quasi-drugs. We have demonstrated that HPFs did not induce primary and cumulative skin irritation, skin sensitization, skin photosensitization, contact phototoxicity, or patch test reactions. Only very mild physical effects were observed on instilling insoluble fullerene powder into rabbit eyes. Therefore, by comparison of these results with previously published data (Mori et al., 2006), we believe that HPFs can be safely utilized in cosmetic ingredients for human skin application (Table 2).

Table 2. Comparative results of the various toxicity tests for the HPFs in our studies

\begin{tabular}{lcc}
\hline Toxicity test & Guideline & HPFs (under GLP) \\
\hline Single-dose toxicity (MLD) & DE $1-24$ & $>2,000 \mathrm{mg} / \mathrm{kg}$ \\
Primary skin irritation & - & No irritation \\
Cumulative skin irritation & - & No irritation \\
Eye irritation & DE $1-24$ & Very mild irritation \\
Skin sensitization (LLNA) & DE $1-24$ & No sensitivity \\
Skin photosensitization & - & No sensitivity \\
Phototoxicity & OECD471, etc. & No toxicity \\
Bacterial reverse mutation (Ames test) & OECD471, etc. & No mutagenicity \\
Chromosomal aberration & - & No mutagenicity \\
Patch test & - & Negative
\end{tabular}

MLD, minimum lethal dose; LLNA, local lymph node assay; HPFs, highly purified fullerenes; GLP, good laboratory practice; DE, drug evaluation; OECD, Organisation for Economic Co-operation and Development. 


\section{ACKNOWLEDGMENTS}

The authors are grateful to Mitsubishi Chemical Safety Institute Ltd. for technical assistance with analysis and metabolism. Animal treatment and measurements were performed by Kashima Laboratory, Mitsubishi Chemical Safety Institute Ltd., Japan.

\section{REFERENCES}

Basso, A.S., Frenkel, D., Quintana, F.J., Costa-Pinto, F.A., PetrovicStojkovic, S., Puckett, L., Monsonego, A., Bar-Shir, A., Engel, Y., Gozin, M. and Weiner, H.L. (2008): Reversal of axonal loss and disability in a mouse model of progressive multiple sclerosis. J. Clin. Invest., 118, 1532-1543.

Beuerle, F., Lebovitz, R. and Hirsch, A. (2008): Antioxidant properties of water-soluble fullerene derivatives. Med. Chem. Pharmacol. Potential of Fullerenes and Carbon Nanotubes, 1, 51-78.

Cai, X., Jia, H., Liu, Z., Hou, B., Luo, C., Feng, Z., Li, W. and Liu, J. (2008): Polyhydroxylated fullerene derivative $\mathrm{C}(60)(\mathrm{OH})(24)$ prevents mitochondrial dysfunction and oxidative damage in an MPP $(+)$-induced cellular model of Parkinson's disease. J. Neurosci. Res., 86, 3622-3634.

Draize, J.H., Woodard, G. and Calvery, H.O. (1944): Methods for the study of irritation and toxicity of substances applied topically to the skin and mucous membranes. J. Pharmacol. Exp. Ther., 82, 377-390.

Fujita, K., Morimoto, Y., Ogami, A., Myojyo, T., Tanaka, I., Shimada, M., Wang, W-N., Endoh, S., Uchida, K., Nakazato, T., Yamamoto, K., Fukui, H., Horie, M., Yoshida, Y., Iwahashi, H. and Nakanishi, J. (2009): Gene expression profiles in rat lung after inhalation exposure to $\mathrm{C}_{60}$ fullerene particles. Toxicology, 258, 47-55.

Kay, J.H. and Calandra, J.C. (1962): Interpretation of eye irritation tests. J. Soc. Cosmetic Chemists, 12, 281-289.

Magnusson, B. and Kligman, A.M. (1969): The identification of contact allergens by animal assay. The guinea pig maximization test. J. Invest. Dermatol., 52, 268-276.

Mori, T., Takada, H., Ito, S., Matsubayashi, K., Miwa, N. and Sawaguchi, T. (2006): Preclinical studies on safety of fullerene upon acute oral administration and evaluation for no mutagenesis. Toxicology, 225, 48-54.

Morikawa, F., Nakayama, Y., Fukuda, M., Hamano, M., Yokoyama, Y., Nagura, T., Ishihara, M. and Toda, K. (1974): Techniques for evaluation of phototoxicity and photoallergy in laboratory animals and man. In: Sunlight and Man: Normal and Abnormal Photobiologic Responses (Pathak, M.A., Harber, L.C., Seiji, M., Kukita, A. and Fitzpatrick, T.B., eds.), pp.529-557, University of Tokyo Press, Tokyo.

Sato, Y., Katsumura, Y., Ichikawa, H., Kobayashi, T., Kozuka, T., Morikawa, F. and Ohta, S. (1981): A modified technique of guinea pig testing to identify delayed hypersensitivity allergens. Contact Dermatitis, 7, 225-237.

Takagi, A., Hirose, A., Nishimura, T., Fukumori, N., Ogata, A., Ohashi, N., Kitajima, S. and Kanno, J. (2008): Induction of mesothelioma in $\mathrm{p} 53+/-$ mouse by intraperitoneal application of multi-wall carbon nanotube. J. Toxicol. Sci., 33, 105-116.

Xiao, L., Matsubayashi, K. and Miwa, N. (2007): Inhibitory effect of the water-soluble polymer-wrapped derivative of fullerene on UVA-induced melanogenesis via downregulation of tyrosi- nase expression in human melanocytes and skin tissues. Arch. Dermatol. Res., 299, 245-257.

Xiao, L., Takada, H., Gan, X. and Miwa, N. (2006): The water-soluble fullerene derivative "Radical Sponge" exerts cytoprotective action against UVA irradiation but not visible-light-catalyzed cytotoxicity in human skin keratinocytes. Bioorg. Med. Chem. Lett., 16, 1590-1595.

Xiao, L., Takada, H., Maeda, K., Haramoto, M. and Miwa, N. (2005): Antioxidant effects of water-soluble fullerene derivatives against ultraviolet ray or peroxylipid through their action of scavenging the reactive oxygen species in human skin keratinocytes. Biomed. Pharmacother., 59, 351-358.

Yudoh, K., Shishido, K., Murayama, H., Yano, M., Matsubayashi, K., Takada, H., Nakamura, H., Masuko, K., Kato, T. and Nishioka, K. (2007): Water-soluble C60 fullerene prevents degeneration of articular cartilage in osteoarthritis via down-regulation of chondrocyte catabolic activity and inhibition of cartilage degeneration during disease development. Arthritis Rheum., 56, 3307-3318. 